\title{
Nonalcoholic fatty liver disease in long-term survivors of childhood-onset craniopharyngioma
}

\author{
So Yoon Jung, \\ Yun Jeong Lee, \\ Hye Jin Lee, MD, \\ Young Ah Lee, MD, PhD \\ Jin Soo Moon, MD, PhD \\ Jae Sung Ko, MD, PhD \\ Sei Won Yang, MD, PhD \\ Choong Ho Shin, MD, PhD \\ Department of Pediatrics, Seoul \\ National University Children's Hospital, \\ Seoul National University College of \\ Medicine, Seoul, Korea
}

Purpose: Hypothalamic obesity in childhood-onset (CO-) craniopharyngioma patients may predispose to nonalcoholic fatty liver disease (NAFLD). This study reviewed the characteristics of NAFLD associated with CO-craniopharyngioma.

Methods: This study retrospectively reviewed 75 patients who underwent surgery for craniopharyngioma while younger than 15 years of age between 2000 and 2016. Results: Elevated aspartate aminotransferase (AST) or alanine aminotransferase (ALT) above $40 \mathrm{IU} / \mathrm{L}$ was observed in 51 of the 75 (68\%) CO-craniopharyngioma patients. Imaging studies were performed in 32 patients with elevated liver enzymes. The estimated prevalence of NAFLD in CO-craniopharyngioma was 47\%. NAFLD was detected in 22 patients (male 59\%, 4.3 \pm 4.0 years after first surgery). The mean age at the time of the initial operation was $9.1 \pm 2.9$ years. Six patients $(27.3 \%)$ were diagnosed within 1 year. Among the 19 patients with initial height and weight data, the body mass index (BMI) $z$-score (BMI_Z) at the time of diagnosis with NAFLD was $1.37 \pm 1.01$ (range, -0.75 to 3.18 ), with 4 patients (18.2\%) being overweight and 9 (40.9\%) being obese. BMI_Z increased above BMI_Z at the time of the operation in 13 patients (68.4\%). The increment in BMI_Z was 1.13 (range, 0.10-2.84). Seventeen patients did not receive growth hormone. An insulin-like growth factor-l level $<3$ rd percentile was observed in 19 patients.

Conclusion: NAFLD is common in survivors of CO-craniopharyngioma and may develop earlier. If the ALT or AST is above $40 \mathrm{IU} / \mathrm{L}$, a diagnostic work-up should be started.

Keywords: Child craniopharyngioma, Nonalcoholic fatty liver disease, Growth hormone deficiency, Hypothalamus, Obesity

\section{Introduction}

Craniopharyngiomas are rare sellar malformations with a low histological grade. Between $30 \%$ and $50 \%$ of all cases are diagnosed in children and adolescents, and childhood-onset (CO-) craniopharyngioma comprises $1.2 \%-4 \%$ of all childhood intracranial tumors, making it the most common pituitary mass in childhood ${ }^{1,2)}$. Craniopharyngioma patients suffer from the visual impairment, anterior and posterior pituitary hormone deficiencies, and severe obesity after tumor resection surgery ${ }^{1)}$. Craniopharyngiomas can cause metabolic syndrome as a result of central obesity, increased insulin resistance, increased blood pressure, hyperlipidemia, and growth hormone $(\mathrm{GH})$ deficiency or inactivity ${ }^{3-5)}$.

As the prevalence of pediatric obesity increases, nonalcoholic fatty liver disease (NAFLD) is increasing in children and adolescents in many developed countries. Although the prevalence of NAFLD in children varies widely depending on the diagnostic methods used, several studies have reported prevalences of $3 \%-10 \%$ in general pediatric populations ${ }^{6}$, and this increases to $50 \%$ in CO-craniopharyngioma patients with hypothalamic involvement ${ }^{7}$. 
NAFLD is defined as the excessive deposition of fat in the liver, leading to a spectrum of hepatic pathologies ranging from simple steatosis in the most benign form to nonalcoholic steatohepatitis (NASH) or cirrhosis in the absence of significant alcohol consumption ${ }^{6,8)}$. Traditionally, fructose ingestion, visceral obesity, insulin resistance, and metabolic syndrome are considered risk factors for NAFLD ${ }^{6,8)}$. Oxidative stress, lipotoxicity, adipocytokines, mitochondrial dysfunction, endoplasmic reticulum stress ${ }^{6}$, and bisphenol $\mathrm{A}^{9)}$ have all been implicated. NAFLD may also coincide with endocrine diseases such as polycystic ovary syndrome, hypothyroidism, GH deficiency, or hypercortisolism ${ }^{10,11}$.

Severe hypothalamic obesity has a significant negative impact on a metabolic function including NAFLD and the quality of life in long-term survivors of CO-craniopharyngioma ${ }^{12-14)}$. NAFLD proved by computed tomography (CT) occurs in about $50 \%$ of young adults with CO-craniopharyngioma and is associated with elevated liver enzymes ${ }^{7}$.

It is essential to understand the characteristics of CO-craniopharyngioma patients to prevent the development of NAFLD and improve their quality of life. This study describes the clinical characteristics of NAFLD in CO-craniopharyngioma patients, such as the frequency, time interval, and predictive factors.

\section{Materials and methods}

\section{Subjects}

The medical records of craniopharyngioma patients cared at Seoul National University Children's Hospital were reviewed retrospectively. During the years reviewed, the goal of the surgery was always radical excision whenever possible. We reviewed 76 patients who had their first surgery before the age of 15 years from January 1, 2000, to February 1,2016 (Fig. 1).

In our institute, liver imaging studies are not performed routinely for craniopharyngioma patients. Out of 75 patients, 32 underwent imaging studies because of elevated liver enzymes. Ultimately, 22 patients were diagnosed with NAFLD based on the imaging studies, and we reviewed the clinical courses of these patients. This study was approved by the Institutional Review Board of Seoul National University Hospital (approval number: 1608-141-787). Written informed consent was obtained from all patients.

\section{Hormone replacement}

Preoperatively, all patients were evaluated regarding the need for replacement therapy with levothyroxine, hydrocortisone, and antidiuretic hormone $(\mathrm{ADH})^{14)}$. Postoperatively, hydrocortisone was tapered to a tolerable dose under $15 \mathrm{mg} / \mathrm{m}^{2} /$ day and thyroid hormone was adjusted according to the free T4 level. Patients who had diabetes insipidus were placed on ADH replacement. Pituitary function tests including GH was done within 1 year of tumor surgery. If the patient agreed to take $\mathrm{GH}$,
GH for stature growth $\left(0.5-0.7 \mathrm{mg} / \mathrm{m}^{2} / \mathrm{wk}\right)$ or $\mathrm{GH}$ for metabolic effect $\left(0.1 \mathrm{mg} / \mathrm{m}^{2} / \mathrm{wk}\right)$ was started approximately 1 year after the final tumor treatment whenever there was no tumor recurrence. Hypogonadotropic hypogonadism was evaluated after the age of 10 years in female or 12 years in a male. All patients had GH deficiency, hypothyroidism, adrenal insufficiency, and diabetes insipidus. Hypogonadism was observed in 21 patients and the gonadal axis was not studied in the remaining case.

\section{Demographics and laboratory assessment}

Height was measured twice with a Harpenden stadiometer (Holtain, Crymych, UK) and weight was measured with a digital scale. The $z$-score of height (height_Z), weight (weight_ $\mathrm{Z}$ ), and body mass index (BMI_Z) were calculated using the 2007 Korean National Growth Charts ${ }^{15}$. The serum aspartate aminotransferase (AST) and alanine aminotransferase (ALT) levels were measured and the normal ranges were $0-40 \mathrm{IU} / \mathrm{L}$ for both. A diagnosis of NAFLD was based on evidence of a fatty liver from liver sonography or abdominal CT. The insulin-like

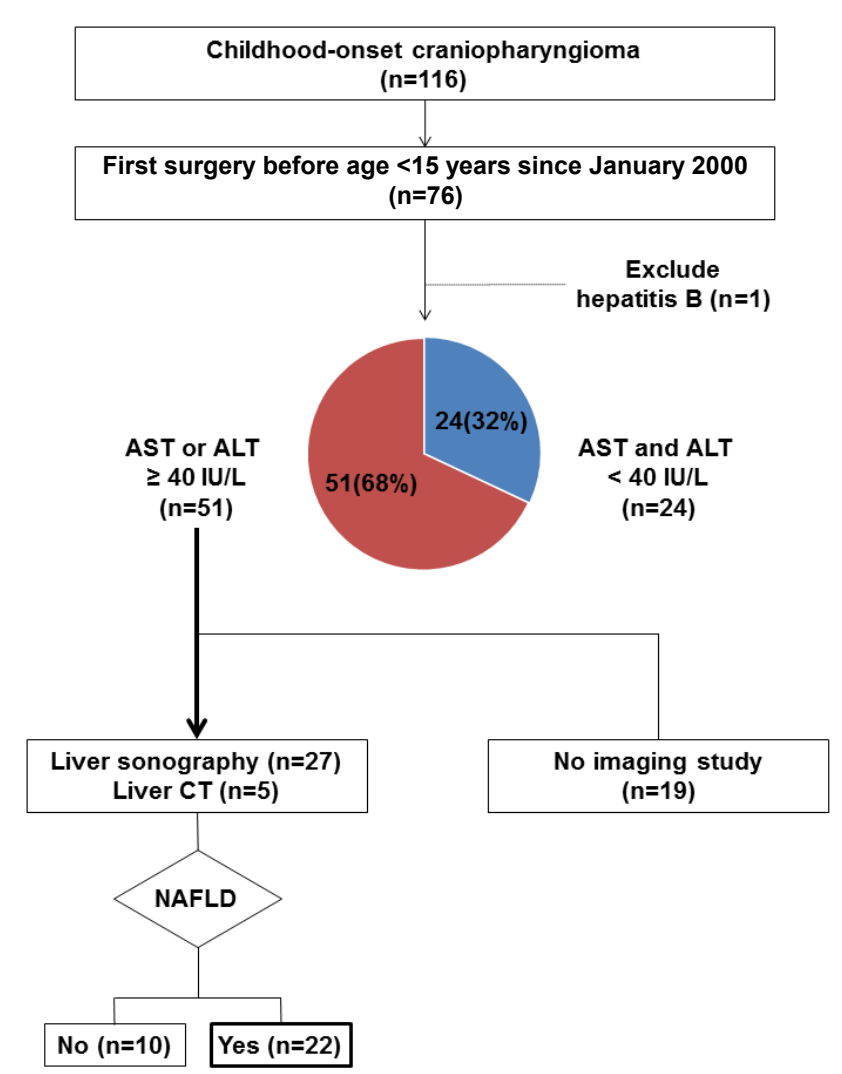

Fig. 1. Study population. We reviewed 76 patients who had their first surgery before the age of 15 years from January 1, 2000 to February 1, 2016. Out of 75 patients, 32 underwent imaging studies because of elevated liver enzymes. Ultimately, 22 patients were diagnosed with NAFLD based on the imaging studies. The estimated prevalence of NAFLD in childhood onsetcraniopharyngioma was $46.8 \%$. AST, aspartate aminotransferase; ALT, alanine aminotransferase; CT, computed tomography; NAFLD, nonalcoholic fatty liver disease. 
growth factor-I (IGF-I) level $<3$ rd percentile was assigned using the Korean data $^{16)}$.

\section{Statistical analysis}

All statistical analyses were conducted with IBM SPSS Statistics ver. 20.0 (IBM Co., Armonk, NY, USA). All continuous variables are described as the mean \pm standard deviation.

\section{Results}

AST or ALT elevation above $40 \mathrm{IU} / \mathrm{L}$ was observed in 51 of the $75(68.0 \%)$ CO-craniopharyngioma patients (Fig. 1). Imaging studies were performed in 32 patients with elevated liver enzymes and NAFLD was detected in 22 patients by CT $(n=5)$ or sonography $(n=17)$. The estimated prevalence of NAFLD in CO-craniopharyngioma was 46.8\% [51×(22/32)/75]. NAFLD was not detected in 10 patients who underwent liver sonography. Only one patient (C11) did a liver biopsy and proved to have NASH.

\section{Clinical characteristics of NAFLD patients at initial operation}

Of the 22 NAFLD patients, 13 (59.1\%) were male patients (Table 1). The mean age at the time of the initial operation was $9.1 \pm 2.9$ years. The preoperative anthropometric data were known in 19 cases. For the 19 patients, the preoperative height $z$-score was $-1.17 \pm 0.87$ and 4 patients $(21.1 \%$ ) had a height_Z $<-2$. The preoperative BMI_Z of the 19 patients was $0.87 \pm 1.22$ with 3 patients (15.8\%) being overweight and 7 patients $(36.8 \%)$ being obese.

\section{Clinical characteristics at diagnosis of NAFLD}

The mean time interval to the diagnosis of NAFLD in the 22 patients after the initial surgery was $4.3 \pm 4.0$ (range, $0-12.2$ ) years (Table 1). The BMI_Z at the time of diagnosis of NAFLD was $1.37 \pm 1.01$. Four patients $(18.2 \%)$ were overweight and 9 patients $(40.9 \%)$ were obese. For the 19 patients with initial height and weight data, BMI_Z increased above BMI_Z at operation in 13 patients (68.4\%) (Fig. 2). The increment in

Table 1. Clinical and biochemical characteristics of nonalcoholic fatty liver disease patients with childhood onset craniopharyngioma

\begin{tabular}{|c|c|c|c|c|c|c|c|c|c|c|c|c|c|}
\hline \multirow{3}{*}{$\begin{array}{l}\text { No. } \\
\text { C01 }\end{array}$} & \multirow{3}{*}{$\begin{array}{l}\text { Sex } \\
\text { F }\end{array}$} & \multicolumn{5}{|c|}{ Preoprative } & \multicolumn{7}{|c|}{ At diagnosis of nonalcoholic liver disease } \\
\hline & & \multirow{2}{*}{$\begin{array}{c}\text { Age (yr) } \\
12.7\end{array}$} & \multirow{2}{*}{$\begin{array}{c}\text { Height } \\
z \text {-score } \\
-1.39\end{array}$} & \multirow{2}{*}{$\begin{array}{c}\begin{array}{c}\text { BMI }\left(\mathrm{kg} / \mathrm{m}^{2}\right) \\
(z \text {-score) }\end{array} \\
22.0(0.94)\end{array}$} & \multirow{2}{*}{$\begin{array}{c}\begin{array}{c}\text { IGF-1 } \\
(\mathrm{ng} / \mathrm{mL})\end{array} \\
62\end{array}$} & \multirow{2}{*}{$\begin{array}{c}\begin{array}{c}\text { Surgical } \\
\text { approach }\end{array} \\
\text { TSA }\end{array}$} & \multirow{2}{*}{$\begin{array}{c}\begin{array}{c}\text { Time } \\
\text { interval } \\
(y r)\end{array} \\
0.0\end{array}$} & \multirow{2}{*}{$\begin{array}{c}\text { Height } \\
z \text {-score } \\
-1.39\end{array}$} & \multirow{2}{*}{$\begin{array}{c}\begin{array}{c}\text { BMI }\left(\mathrm{kg} / \mathrm{m}^{2}\right) \\
(z \text {-score })\end{array} \\
22.0(0.94)\end{array}$} & \multirow{2}{*}{$\begin{array}{c}\begin{array}{c}\mathrm{IGF}-1 \\
(\mathrm{ng} / \mathrm{mL})\end{array} \\
62\end{array}$} & \multicolumn{2}{|c|}{ GH replacement/duration } & \multirow{2}{*}{$\begin{array}{c}\text { Sex hormone } \\
\text { replacement } \\
\text { - }\end{array}$} \\
\hline & & & & & & & & & & & No (OP within $1 \mathrm{yr}$ ) & - & \\
\hline $\mathrm{CO} 2$ & M & 14.3 & -1.94 & $18.3(-0.75)$ & 45 & Craniotomy & 0.0 & -1.94 & $18.3(-0.75)$ & 45 & No (OP within $1 \mathrm{yr}$ ) & - & - \\
\hline $\mathrm{CO3}$ & M & 10.1 & -0.98 & $18.6(0.26)$ & $<10$ & Craniotomy & 0.0 & -0.98 & $19.8(0.63)$ & $<10$ & No (OP within 1 yr) & - & - \\
\hline $\mathrm{CO} 4$ & M & 10.9 & -2.82 & $19.6(0.37)$ & 238 & Craniotomy & 0.1 & -2.82 & $22.2(1.08)$ & 54 & No (OP within $1 \mathrm{yr}$ ) & - & - \\
\hline C05 & $\mathrm{F}$ & 11.0 & -0.80 & $24.2(1.8)$ & $<10$ & Craniotomy & 0.2 & -0.88 & $26.0(2.11)$ & $<10$ & No (OP within $1 \mathrm{yr}$ ) & - & - \\
\hline C06 & M & 8.7 & -2.08 & $17.3(0.1)$ & 51 & TSA & 0.8 & -1.49 & $20.5(0.98)$ & 51 & No (recurrence) & - & - \\
\hline $\mathrm{CO}$ & M & 13.6 & -0.42 & $19.3(-0.23)$ & 474 & TSA & 1.1 & -1.27 & $22.2(0.49)$ & 82 & No (RT within 1 yr) & - & - \\
\hline C08 & M & 9.5 & -0.75 & $26.0(2.13)$ & 63 & Craniotomy & 1.6 & -0.78 & $26.3(1.86)$ & 67 & No (good GV) & - & - \\
\hline Co9 & $\mathrm{F}$ & 12.5 & -0.45 & $14.7(-1.96)$ & - & Craniotomy & 2.2 & 0.26 & $22.8(0.88)$ & 73 & No (recurrence) & 1.25 & - \\
\hline $\mathrm{C} 10$ & $\mathrm{~F}$ & 7.4 & -2.31 & $18.8(1.27)$ & - & Craniotomy & 2.5 & -0.11 & $26.6(2.46)$ & $<10$ & No (imbalance) & 0.31 & - \\
\hline C11 & M & 8.2 & -1.41 & $15.0(-0.97)$ & 101 & Craniotomy & 2.6 & -0.80 & $23.3(1.34)$ & 79 & No (recurrence) & - & - \\
\hline $\mathrm{C} 12$ & $\mathrm{~F}$ & 5.8 & -1.79 & $16.3(0.53)$ & $<10$ & Craniotomy & 2.9 & 0.90 & $29.0(3.09)$ & 31 & No (recurrence) & - & - \\
\hline $\mathrm{C} 13$ & M & 2.8 & - & - & - & Craniotomy & 3.6 & -2.11 & $16.7(0.43)$ & 371 & Yes & * & - \\
\hline C14 & M & 8.5 & - & - & - & Craniotomy & 5.3 & -0.90 & $27.8(1.75)$ & 53 & No (recurrence) & - & - \\
\hline $\mathrm{C} 15$ & M & 10.0 & - & - & - & Craniotomy & 5.4 & -2.00 & $25.4(1.2)$ & 45 & No (recurrence) & 1.54 & - \\
\hline C16 & M & 6.4 & 0.43 & $19.6(1.63)$ & $<10$ & Craniotomy & 6.3 & 1.80 & $26.9(1.72)$ & 30 & No (recurrence) & 1.44 & - \\
\hline C17 & M & 7.0 & -2.48 & $19.8(1.49)$ & - & Craniotomy & 7.8 & 0.87 & $35.8(2.76)$ & 86 & No (refusal) & 5.37 & - \\
\hline C18 & $\mathrm{F}$ & 5.8 & -0.80 & $19.4(1.92)$ & - & Craniotomy & 8.4 & 0.77 & $19.0(-0.3)$ & 52 & Yes & 0.37 & T-E 50 mg \\
\hline C19 & $\mathrm{F}$ & 5.9 & -0.40 & $18.7(1.69)$ & - & TSA & 8.9 & 0.92 & $24.1(1.22)$ & 17 & No (recurrence) & - & $\begin{array}{l}\text { E-V } 2 \text { mg, } \\
\text { MP } 5 \text { mg }\end{array}$ \\
\hline $\mathrm{C} 20$ & $\mathrm{~F}$ & 8.0 & -0.34 & $24.4(2.54)$ & - & Craniotomy & 10.1 & 2.34 & $23.7(0.94)$ & 124 & Yes (intermittent use) & 3.32 & $\begin{array}{l}\text { E-V } 1 \text { mg, } \\
\text { MP } 5 \text { mg }\end{array}$ \\
\hline C21 & M & 11.0 & -0.59 & $27.0(2.02)$ & 133 & Craniotomy & 11.4 & 0.08 & $39.4(3.18)$ & 158 & Yes & 6.49 & $\begin{array}{l}\text { E-V } 2 \text { mg, } \\
\text { MP } 5 \text { mg }\end{array}$ \\
\hline $\mathrm{C} 22$ & $\mathrm{~F}$ & 10.3 & -0.91 & $23.5(1.81)$ & - & Craniotomy & 12.2 & 0.63 & $27.9(2.05)$ & 24 & Yes (poor compliance) & 7.49 & $\mathrm{~T}-\mathrm{U} 1,000 \mathrm{mg}$ \\
\hline
\end{tabular}

BMI, body mass index; IGF-I, insulin-like growth factor-l; GH, growth hormone; TSA, transsphenoidal approach; OP, operation; RT, radiation therapy; GV, growth velocity; T-E, testosterone enanthate; E-V, estradiol valerate; MP, medroxyprogesterone; T-U, testosterone undecanoate. *Duration of $\mathrm{GH}$ replacement is not known due to outside treatment. 


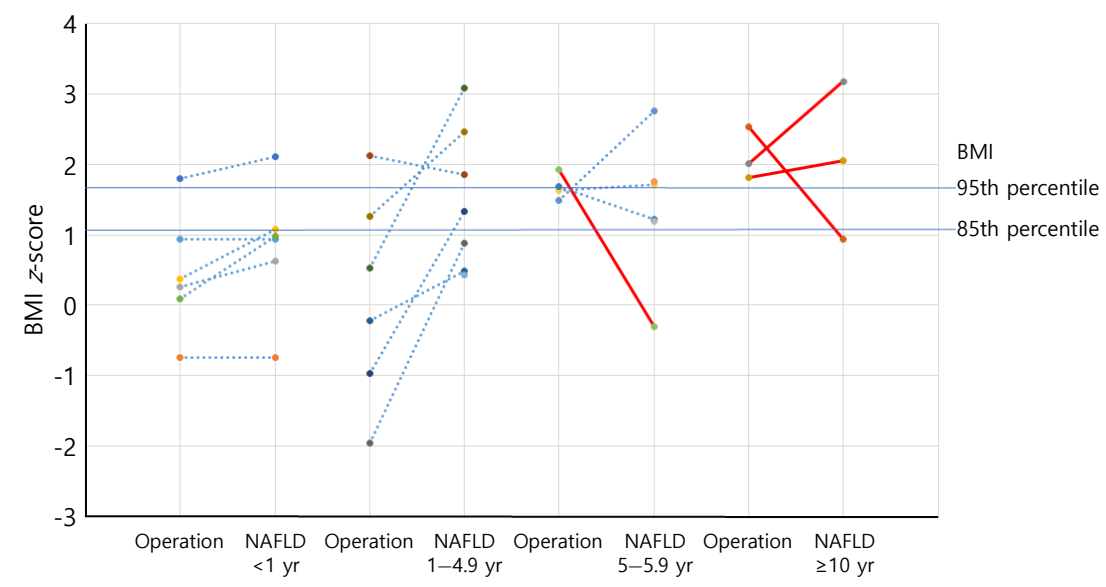

Fig. 2. Body mass index $z$-score (BMI_Z) change after initial operation. The red lines indicate the case who was given GH at NAFLD diagnosis. BMI_Z increased above BMI_Z at the time of the operation in 13 patients (68.4\%). The mean increment in BMI_Z was 1.13 (range, 0.10-2.84). NAFLD, nonalcoholic fatty liver disease.

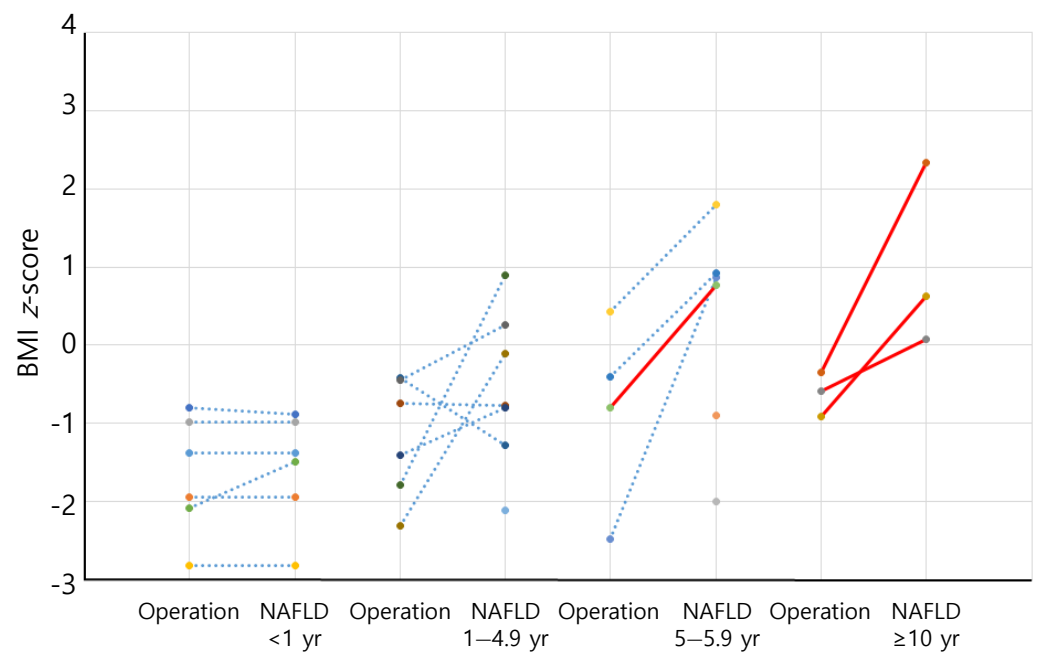

Fig. 3. Height $z$-score (Height_Z) change after initial operation. The red lines indicate the case who was given GH at NAFLD diagnosis. The preoperative Height_Z was $-1.17 \pm 0.87$. NAFLD, nonalcoholic fatty liver disease.

BMI_Z was 1.13 (range, $0.10-2.84$ ). The height_Z $\mathrm{Z}$ at the time of diagnosis of NAFLD was $-0.40 \pm 1.35$ (range, -2.82 to 2.34 ) (Fig. 3).

Six patients (C01-C06, 27.3\%) were diagnosed with NAFLD within 1 year. One was diagnosed preoperatively and three patients were diagnosed within 1 month $(4,11$, and 19 days) postoperatively. All of them were given thyroid hormone, hydrocortisone, and $\mathrm{ADH}$, but not GH. After the initial operation, BMI increased rapidly in 4 patients. One patient had a height_Z increment of 0.59 within 0.8 years without GH treatment.

Seven patients (C07-C13,31.8\%) were diagnosed with NAFLD within 1 to 4.9 years after the operation. Only 1 patient (C13) received GH and all seven received thyroid hormone, hydrocortisone, and ADH. Of 6 patients $(\mathrm{C} 07-\mathrm{C} 12)$ who did not receive GH treatment, BMI_Z increased above BMI_Z at operation in 5 patients (83.3\%). The increment in BMI_Z was 1.92 (range, $0.71-2.84$ ). Only 1 patient (C08) showed a decrease in BMI_Z, but this patient was severely obese. Of the 6 patients, 4 (66.7\%) showed catch-up growth (Fig. 3).

Nine patients (C14-C22, 40.9\%) were diagnosed with NAFLD more than 5 years after the operation, and the average time interval was $8.4 \pm 2.5$ years. All of them were given thyroid hormone, hydrocortisone, and ADH. Six patients received sex steroids and 4 of these patients received GH. Height $\mathrm{Z}$ increased in seven patients $(\mathrm{C} 16-\mathrm{C} 22)$ regardless of $\mathrm{GH}$ treatment. Two of the 4 patients who received GH showed a decrease in BMI_Z. 


\section{Liver enzyme and biochemical profiles at diagnosis of NAFLD}

All 22 patients with NAFLD (100\%) had an elevation of either AST or ALT over the normal range (40 IU/L) before they were diagnosed with NAFLD. ALT $\geq 60 \mathrm{IU} / \mathrm{L}$ was observed in 15 patients and AST $\geq 60$ was found in 17 patients. An ALT/ AST ratio $>1$ was observed in 14 patients. The lipid profile was measured in 13 patients (Table 2). Hypertriglyceridemia was found in 9 patients and hypo-HDL $(<40 \mathrm{mg} / \mathrm{dL})$ was observed in 7. Homeostasis model assessment-insulin resistance level greater than the mean level of normal South Korean adolescents ${ }^{17)}$ was observed in 9 of 12 patients. Impaired fasting glucose was observed in 4 patients. Hyperuricemia (uric acid $\geq 7$ $\mathrm{mg} / \mathrm{dL}$ ) was seen in 9 patients.

\section{GH treatment}

Only 5 patients (C13, C18, C20-C22) were given GH at NAFLD diagnosis (Table 1). The reasons for not giving 17 patients $\mathrm{GH}$ included tumor recurrence or a risk of tumor recurrence $(n=8,47.1 \%)$ or within a year after surgery or

Table 2. Metabolic profiles of nonalcoholic fatty liver disease patients with childhood onset craniopharyngioma

\begin{tabular}{|c|c|c|c|c|c|c|}
\hline No. & $\begin{array}{c}\text { AST/ALT } \\
(\mathrm{IU} / \mathrm{L})\end{array}$ & $\begin{array}{c}\text { Chol/TG/ } \\
\mathrm{LDL} / \mathrm{HDL} \\
\text { (mg/dL) }\end{array}$ & $\begin{array}{c}\mathrm{FBS} \\
(\mathrm{mg} / \mathrm{dL})\end{array}$ & $\begin{array}{c}\text { Insulin } \\
(\mu \mathrm{lU} / \mathrm{mL})\end{array}$ & HOMA-IR & $\begin{array}{c}\mathrm{UA} \\
(\mathrm{mg} / \mathrm{dL})\end{array}$ \\
\hline C01 & $124 / 144$ & $177 / 152 / 118 / 49$ & 85 & - & - & 7.7 \\
\hline $\mathrm{CO} 2$ & $63 / 90$ & 187/-/-/- & 109 & 9.2 & 2.5 & 3.9 \\
\hline $\mathrm{CO3}$ & $371 / 423$ & 294/-/-/- & 87 & - & - & 3.1 \\
\hline CO4 & $118 / 187$ & 153/73/93/47 & 83 & 8.3 & 1.7 & 3.8 \\
\hline C05 & $95 / 127$ & 172/-/-/- & 98 & - & - & 6.5 \\
\hline C06 & $61 / 56$ & 219/264/138/33 & 94 & - & - & 7.8 \\
\hline CO7 & $45 / 140$ & $184 / 175 / 110 / 36$ & 96 & 8.0 & 1.9 & 11.2 \\
\hline C08 & $79 / 33$ & 163/-/-/- & 97 & - & - & 6.7 \\
\hline Co9 & $217 / 153$ & $160 /-/-/-$ & 87 & 17.7 & 3.8 & 6.6 \\
\hline $\mathrm{C} 10$ & $54 / 48$ & $143 / 368 / 50 / 20$ & 91 & - & - & 9.9 \\
\hline C11 & $60 / 120$ & 234/404/85/37 & 99 & 17.7 & 4.3 & 5.0 \\
\hline C12 & $55 / 62$ & 117/-/-/- & 91 & - & - & 6.5 \\
\hline $\mathrm{C} 13$ & $83 / 94$ & 124/-/-/- & 102 & - & - & 3.9 \\
\hline C14 & $40 / 40$ & $141 / 97 / 81 / 40$ & 91 & 43.9 & 9.9 & 6.2 \\
\hline C15 & $64 / 108$ & 203/202/132/41 & 84 & 14.5 & 3.0 & 8.0 \\
\hline C16 & $73 / 121$ & $125 / 171 / 76 / 34$ & 89 & 42.8 & 9.4 & 6.0 \\
\hline C17 & $125 / 42$ & 189/118/119/46 & 88 & 15.3 & 3.3 & 7.3 \\
\hline C18 & $61 / 37$ & 140/92/86/40 & 124 & 18.8 & 5.8 & 9.3 \\
\hline C19 & $108 / 142$ & $197 / 231 / 163 / 26$ & 76 & 16.8 & 3.2 & 5.4 \\
\hline $\mathrm{C} 20$ & $45 / 41$ & 195/-/-/- & 102 & - & - & 4.5 \\
\hline C21 & $64 / 93$ & 163/-/-/- & 90 & - & - & 10.6 \\
\hline $\mathrm{C} 22$ & $75 / 96$ & $176 / 260 / 86 / 38$ & 89 & 16.9 & $3.7-$ & 7.1 \\
\hline
\end{tabular}

AST, aspartate aminotransferase; ALT, alanine aminotransferase; Chol, cholesterol; TG, triglyceride; LDL, low-density lipoprotein cholesterol; HDL, high-density lipoprotein cholesterol; FBS, fasting blood sugar; HOMA-IR, homeostasis model assessmentinsulin resistance; $U A$, uric acid. radiation therapy ( $\mathrm{n}=6,35.3 \%$ ) or other causes (body imbalance, refusal, normal growth velocity). An IGF-I level $<3$ rd percentile was observed in 19 patients (Table 1). Two adults (C20, $\mathrm{C} 21$ ) with IGF-I $>100 \mathrm{ng} / \mathrm{mL}$ had received $\mathrm{GH}$ treatment but developed NAFLD more than 10 years after the initial operation.

\section{Discussion}

NAFLD was common in CO-craniopharyngioma and the prevalence was $46.8 \%$ in CO-craniopharyngioma and especially $68.8 \%$ in CO-craniopharyngioma with liver aminotransferase $\geq 40$ IU/L. NAFLD may develop even within a year after craniopharyngioma surgery.

Genetics, epigenetics, environmental factors, insulin resistance, and obesity all influence fat accumulation in the liver. The fatty liver is then predisposed to oxidative stress, mitochondrial dysfunction, proinflammatory cytokine imbalances, and stellate cell activation, which lead to necro-inflammation and fibrosis ${ }^{18)}$. Obesity is the main risk factor for pediatric NAFLD and insulin resistance, hyperglycemia, and dyslipidemia are also strongly associated with NAFLD.

While increasing the survival of CO-craniopharyngioma patients, hypothalamic obesity may predispose to NAFLD, metabolic syndrome, and a poor quality of life ${ }^{12-14,19)}$. Few studies have focused on NAFLD in craniopharyngioma ${ }^{7)}$. Therefore, we reviewed the clinical characteristics of NAFLD in CO-craniopharyngioma patients.

In this study, we used ALT or AST $\geq 40 \mathrm{IU} / \mathrm{L}$ as a cutoff for imaging studies. This level exceeds the level of normal South Korean adolescents, for whom the normal AST level (IU/L) is $21.4 \pm 6.3$ in boys and $19.0 \pm 5.0$ in girls and the normal ALT level (IU/L) is $15.4 \pm 6.3$ in boys and $12.7 \pm 5.2$ in girls ${ }^{17)}$. A high serum ALT within the normal range increases the risk of all components of metabolic syndrome. In this study, 2 patients (C08, C18) with NAFLD showed ALT level of 33 and 37 IU/L but AST level 79 and $61 \mathrm{IU} / \mathrm{L}$ respectively. Generally, it is known that initial NAFLD state correlates better with elevated ALT than AST. However, ALT under $40 \mathrm{IU} / \mathrm{L}$ cannot exclude the possibility of NAFLD ${ }^{20)}$. ALT or AST may be within the normal range in CO-craniopharyngioma with $\mathrm{NAFLD}^{7 \text { ) }}$.

Given the progressive nature of hypothalamic obesity, inadequate $\mathrm{GH}$ replacement, hypogonadism in $\mathrm{CO}$-craniopharyngioma, and the invasiveness of a liver biopsy, the exact prevalence of NAFLD or especially NASH in COcraniopharyngioma is not clear. In this study, we observed AST or ALT elevation $\geq 40 \mathrm{IU} / \mathrm{L}$ in approximately $68 \%$ of COcraniopharyngioma patients. Also, CT or sonographic findings typical of NAFLD were observed in $68 \%$ of the cases that underwent imaging studies. This result is consistent with that of a recently published study that showed NAFLD occurs in about $50 \%$ of CO-craniopharyngioma patients with hypothalamic involvement more than 5 years after the craniopharyngioma diagnosis $^{7)}$. In the United States, liver transplants attributed 
to NAFLD-related liver disease increased from $1.2 \%$ in 2001 to $9.7 \%$ by 2009 . The recipients were older, more likely to be female, and had a higher $\mathrm{BMI}^{21)}$. While simple steatosis carries a minimal risk of cirrhosis and liver failure in adults, NAFLD appears to follow a more aggressive course in pediatric cases than in adults with NAFLD ${ }^{22-25}$. The natural course of NAFLD in patients with hypothalamic and pituitary dysfunction may be more aggressive than the course of NAFLD in the general population. Adams et al ${ }^{26)}$, reported that NAFLD developed relatively quickly (average, 6.4 years) in patients with pituitary/ hypothalamic dysfunction (age range, 9-78 years) and the liver disease in these patients was severe; $60 \%$ of 10 patients who underwent biopsies had cirrhosis, and $14.3 \%$ of 18 NAFLD patients were either transplanted or died during follow-up.

Craniopharyngiomas have many features that can affect the development or aggravation of NAFLD independently or synergistically. Weight gain occurs before the diagnosis, progresses rapidly during the first 6-12 months after treatment, and results in severe obesity in half of the patients ${ }^{1)}$. Our study showed that NAFLD could develop very early, even at the diagnosis of craniopharyngioma, and these NAFLD patients gained more weight during this period. The obesity in these children is related to hypothalamic dysfunction, resulting in disrupted or impaired sensitivity to feeding-related signals involving leptin, insulin, and ghrelin, and reductions in the basal metabolic rate, sleep disturbance, and physical inactivity ${ }^{3,4,27)}$. Children with craniopharyngioma and hypothalamic obesity have more features of metabolic syndrome and insulin resistance than BMI-matched controls ${ }^{28,29)}$. NAFLD was observed in 50\% of CO-craniopharyngioma patients, who tend to have more severe insulin resistance ${ }^{30}$. The relationship between NAFLD and metabolic syndrome is bidirectional, in that NAFLD can predispose to metabolic syndrome features, which can, in turn, exacerbate NAFLD or increase the development risk in those without a pre-existing diagnosis ${ }^{31)}$.

In our study, dyslipidemia was observed in some NAFLD patients, but dyslipidemia or hyperuricemia are insufficient as a predictor of NAFLD. NAFLD is related to endocrine diseases such as hypogonadism, hypothyroidism, GH deficiency, and hypercortisolism ${ }^{11}$. NAFLD is more prevalent in hypopituitarism patients than in control subjects, and severe GH deficiency predisposes to a serious degree of hepatic steatosis in NAFLD ${ }^{32}$. For 17 of 22 patients (77.3\%), no GH was given before diagnosing NAFLD. The effect of GH replacement is controversial. In adults with GH deficiency, GH replacement improves the serum liver enzyme levels and, to optimize this effect, it is important to avoid body weight gain ${ }^{33)}$. It is not clear whether GH replacement improves the NAFLD associated with CO-craniopharyngioma. Although GH therapy induced excellent linear growth in CO-craniopharyngioma patients, it failed to ameliorate the hypothalamic obesity ${ }^{14,34)}$. In our study, the course of NAFLD based on ALT or AST ranged from improvement, to waxing and waning, or to persistent, regardless of GH replacement during follow-up. We think that patients who recover from NAFLD or have normal liver function have a lifetime chance of developing NAFLD because risk factors such as obesity, inactivity, sleep disturbance, and metabolic syndrome may worsen at any time. IGF-I directly modulates the expression of acute-phase reactants; decreasing C-reactive protein and fibrinogen levels and circulating IGF-I levels showed inverse correlations with the NAFLD fibrosis score and inflammatory biomarkers ${ }^{35}$. An IGF-I level<3rd percentile was observed in 19 NAFLD patients in our study. Although the IGF-I level was low, some patients showed catch-up growth of height at the time of diagnosis with NAFLD. The normal growth despite GH deficiency may be explained by a complex series of metabolic events, including obesity-induced hyperinsulinism ${ }^{1)}$. Normal growth does not guarantee that the IGF-I level is sufficient to prevent NAFLD.

Preoperative and postoperative hypothalamic damage may contribute to postoperative weight gain ${ }^{14)}$ and poor quality of life ${ }^{1)}$. In this study, most cases had surgeries through craniotomy rather than transsphenoidal approach (TSA) because TSA was used in some patients with favorable tumor location since 2010. We did not review the degree of hypothalamic damage in this study and this is one of the limitations.

There is no proven, safe, effective treatment for NAFLD ${ }^{18,36)}$ or hypothalamic obesity ${ }^{5)}$ in children. Although lifestyle modification can improve NAFLD in many children ${ }^{18,36)}$, lifestyle intervention is useless in hypothalamic obesity ${ }^{5}$. To improve the quality of life and metabolic condition, treatment should focus on preserving the hypothalamic function and optimizing lifestyle, including adherence to medical therapy, nutrition, physical activity, sleeping, social skills, and mental wellbeing.

This retrospective study had some limitation. First, we could not routinely check the biochemical parameters (liver enzyme, lipid, glucose, and insulin), lifestyle (diet, physical activity, and daytime somnolence), total or visceral body fat, and imaging studies in all patients. Second, ultrasonography was not performed in some patients with ALT or AST elevation $\geq 40 \mathrm{IU} / \mathrm{L}$. Third, NAFLD could be missed in some cocraniopharyngioma patients with ALT or AST $<40 \mathrm{IU} / \mathrm{L}$ in these clinical settings.

In conclusion, NAFLD is common in survivors of CO-craniopharyngioma and may develop earlier than in simple obesity. If ALT or AST is elevated above $40 \mathrm{IU} / \mathrm{L}$, the child should undergo noninvasive examinations, including ultrasonography, serum biomarkers, and transient elastography. All patients should receive the intensive, individualized lifestyle interventions as soon as possible to decrease the risk of progressive obesity, metabolic syndrome, and NAFLD.

\section{Conflict of interest}

No potential conflict of interest relevant to this article was reported. 


\section{References}

1. Müller HL. Craniopharyngioma. Endocr Rev 2014;35:51343.

2. Sterkenburg AS, Hoffmann A, Gebhardt U, Warmuth-Metz M, Daubenbüchel AM, Müller HL. Survival, hypothalamic obesity, and neuropsychological/psychosocial status after childhood-onset craniopharyngioma: newly reported longterm outcomes. Neuro Oncol 2015;17:1029-38.

3. Kim JH, Choi JH. Pathophysiology and clinical characteristics of hypothalamic obesity in children and adolescents. Ann Pediatr Endocrinol Metab 2013;18:161-7.

4. Iughetti L, Bruzzi P. Obesity and craniopharyngioma. Ital J Pediatr 2011;37:38.

5. Lustig RH. Hypothalamic obesity after craniopharyngioma: mechanisms, diagnosis, and treatment. Front Endocrinol (Lausanne) 2011;2:60.

6. Della Corte C, Mazzotta AR, Nobili V. Fatty liver disease and obesity in youth. Curr Opin Endocrinol Diabetes Obes 2016;23:66-71.

7. Hoffmann A, Bootsveld K, Gebhardt U, Daubenbüchel AM, Sterkenburg AS, Müller HL. Nonalcoholic fatty liver disease and fatigue in long-term survivors of childhood-onset craniopharyngioma. Eur J Endocrinol 2015;173:389-97.

8. Ko JS. Nonalcoholic fatty liver disease. Korean J Gastroenterol 2010;56:6-14.

9. Lang IA, Galloway TS, Scarlett A, Henley WE, Depledge $\mathrm{M}$, Wallace RB, et al. Association of urinary bisphenol A concentration with medical disorders and laboratory abnormalities in adults. JAMA 2008;300:1303-10.

10. Yoon JM, Ko JS, Seo JK, Shin CH, Yang SW, Moon JS, et al. Nonalcoholic Fatty Liver Disease in Children with Hypopituitarism. Korean J Pediatr Gastroenterol Nutr 2010;13:51-7.

11. Marino L, Jornayvaz FR. Endocrine causes of nonalcoholic fatty liver disease. World J Gastroenterol 2015;21:11053-76.

12. Müller HL, Gebhardt U, Teske C, Faldum A, Zwiener I, Warmuth-Metz M, et al. Post-operative hypothalamic lesions and obesity in childhood craniopharyngioma: results of the multinational prospective trial KRANIOPHARYNGEOM 2000 after 3-year follow-up. Eur J Endocrinol 2011;165:17-24.

13. Kendall-Taylor P, Jönsson PJ, Abs R, Erfurth EM, Koltowska-Häggström M, Price DA, et al. The clinical, metabolic and endocrine features and the quality of life in adults with childhood-onset craniopharyngioma compared with adult-onset craniopharyngioma. Eur J Endocrinol 2005; 152:557-67.

14. Park SW, Jung HW, Lee YA, Shin CH, Yang SW, Cheon JE, et al. Tumor origin and growth pattern at diagnosis and surgical hypothalamic damage predict obesity in pediatric craniopharyngioma. J Neurooncol 2013;113:417-24.

15. Moon JS, Lee SY, Nam CM, Choi JM, Choe BK, Seo JW, et al. 2007 Korean National Growth Charts: review of developmental process and an outlook. Korean J Pediatr
2008;51:1-25.

16. Hyun SE, Lee BC, Suh BK, Chung SC, Ko CW, Kim HS, et al. Reference values for serum levels of insulin-like growth factor-I and insulin-like growth factor binding protein-3 in Korean children and adolescents. Clin Biochem 2012;45:16-21.

17. Park JH, Kim SH, Park S, Park MJ. Alanine aminotransferase and metabolic syndrome in adolescents: the Korean National Health and Nutrition Examination Survey Study. Pediatr Obes 2014;9:411-8.

18. Berardis S, Sokal E. Pediatric non-alcoholic fatty liver disease: an increasing public health issue. Eur J Pediatr 2014;173:131-9.

19. Crom DB, Smith D, Xiong Z, Onar A, Hudson MM, Merchant TE, et al. Health status in long-term survivors of pediatric craniopharyngiomas. J Neurosci Nurs 2010;42:323-8

20. Mofrad P, Contos MJ, Haque M, Sargeant C, Fisher RA, Luketic VA, et al. Clinical and histologic spectrum of nonalcoholic fatty liver disease associated with normal ALT values. Hepatology 2003;37:1286-92.

21. Charlton MR, Burns JM, Pedersen RA, Watt KD, Heimbach JK, Dierkhising RA. Frequency and outcomes of liver transplantation for nonalcoholic steatohepatitis in the United States. Gastroenterology 2011;141:1249-53.

22. Temple JL, Cordero P, Li J, Nguyen V, Oben JA. A guide to non-alcoholic fatty liver disease in childhood and adolescence. Int J Mol Sci 2016;17(6). pii: E947. https://doi. org/10.3390/ijms17060947.

23. Holterman A, Gurria J, Tanpure S, DiSomma N. Nonalcoholic fatty liver disease and bariatric surgery in adolescents. Semin Pediatr Surg 2014;23:49-57.

24. Holterman AX, Guzman G, Fantuzzi G, Wang H, Aigner K, Browne A, et al. Nonalcoholic fatty liver disease in severely obese adolescent and adult patients. Obesity (Silver Spring) 2013;21:591-7.

25. Feldstein AE, Charatcharoenwitthaya P, Treeprasertsuk S, Benson JT, Enders FB, Angulo P. The natural history of non-alcoholic fatty liver disease in children: a follow-up study for up to 20 years. Gut 2009;58:1538-44.

26. Adams LA, Feldstein A, Lindor KD, Angulo P. Nonalcoholic fatty liver disease among patients with hypothalamic and pituitary dysfunction. Hepatology 2004;39:909-14.

27. Holmer H, Pozarek G, Wirfält E, Popovic V, Ekman B, Björk J, et al. Reduced energy expenditure and impaired feeding-related signals but not high energy intake reinforces hypothalamic obesity in adults with childhood onset craniopharyngioma. J Clin Endocrinol Metab 2010;95:5395-402.

28. Simoneau-Roy J, O'Gorman C, Pencharz P, Adeli K, Daneman D, Hamilton J. Insulin sensitivity and secretion in children and adolescents with hypothalamic obesity following treatment for craniopharyngioma. Clin Endocrinol (Oxf) 2010;72:364-70.

29. Srinivasan S, Ogle GD, Garnett SP, Briody JN, Lee JW, 
Cowell CT. Features of the metabolic syndrome after childhood craniopharyngioma. J Clin Endocrinol Metab 2004;89:81-6.

30. Sahakitrungruang T, Klomchan T, Supornsilchai V, Wacharasindhu S. Obesity, metabolic syndrome, and insulin dynamics in children after craniopharyngioma surgery. Eur J Pediatr 2011;170:763-9.

31. Wainwright P, Byrne CD. Bidirectional Relationships and Disconnects between NAFLD and Features of the Metabolic Syndrome. Int J Mol Sci 2016;17:367.

32. Hong JW, Kim JY, Kim YE, Lee EJ. Metabolic parameters and nonalcoholic fatty liver disease in hypopituitary men. Horm Metab Res 2011;43:48-54.

33. Matsumoto R, Fukuoka H, Iguchi G, Nishizawa H, Bando $\mathrm{H}$, Suda K, et al. Long-term effects of growth hormone replacement therapy on liver function in adult patients with growth hormone deficiency. Growth Horm IGF Res 2014;24:174-9.

34. Geffner M, Lundberg M, Koltowska-Häggström M, Abs R, Verhelst J, Erfurth EM, et al. Changes in height, weight, and body mass index in children with craniopharyngioma after three years of growth hormone therapy: analysis of KIGS (Pfizer International Growth Database). J Clin Endocrinol Metab 2004;89:5435-40.

35. Hribal ML, Procopio T, Petta S, Sciacqua A, Grimaudo S, Pipitone RM, et al. Insulin-like growth factor-I, inflammatory proteins, and fibrosis in subjects with nonalcoholic fatty liver disease. J Clin Endocrinol Metab 2013;98:E304-8.

36. Schwimmer JB. Clinical advances in pediatric nonalcoholic fatty liver disease. Hepatology 2016;63:1718-25. 